\title{
Estudo e caracterização de propriedades da argila esmectita na remoção de corantes têxteis
}

\author{
Study and characterization of properties smectite \\ clay on removal of textile dyes
}

\author{
V. F. B. Mello ${ }^{1}$; J. Gama ${ }^{1}$ \\ J. M. Ferreira ${ }^{1}$; O. S. Barauna ${ }^{2}$, \\ J. F. T. Jucá ${ }^{3}$, M. A. Motta Sobrinho ${ }^{1,3}$
}

\author{
${ }^{1}$ Laboratório de Processos e Tecnologias Ambientais - LPTA - DEQ/UFPE CEP: 50740-521, Recife, PE. \\ e-mail: vfbmello@yahoo.com.br, julliizinha@yahoo.com.br, joelma@ufpe.br, mottas@ufpe.br \\ ${ }^{2}$ Instituto de Tecnologia de Pernambuco -ITEP - CEP: 50740-540, Recife, PE. \\ e-mail: osmar.barauna@gmail.com \\ ${ }^{3}$ Grupo de Resíduos Sólidos - GRS - DECivil/UFPE CEP:50740-520, Recife, PE. \\ e-mail: jucah@ufpe.br, mottas@ufpe.br
}

\section{RESUMO}

O processo na indústria têxtil, principalmente nas etapas de tingimento e acabamento, requer um grande volume de água. A eliminação desses produtos tóxicos é atualmente um dos mais importantes assuntos em controle de poluição, o que tem levado os pesquisadores a buscar novas técnicas e ferramentas mais poderosas para diminuir ou eliminar a toxicidade dos efluentes líquidos formado em seus distintos processos, sempre levando em conta a eficiência, baixo custo e as regulamentações e legislações voltadas à proteção ambiental. Neste trabalho foi avaliada a aplicação de um resíduo argiloso em processos de tratamento de efluentes de indústrias têxteis para remoção de corantes. Foi realizado um estudo de caracterização do adsorvente através da análise da área superficial e do volume poroso (BET), assim como também a análise de presença de minerais do grupo da esmectita (difração de raios-X). Também foi realizada a otimização do processo adsortivo através da técnica de planejamento fatorial para os corantes Nylosan Azul Brilhante e Azul Anil Op. A análise de BET mostrou que o tratamento térmico provocou uma redução na área superficial de $13,3 \%$, todavia provocou um aumento no tamanho dos poros de $21,2 \%$. A análise dos difratogramas de raios $\mathrm{X}$ das amostras in natura indicou a presença dos grupos minerais esmectita, caulinita e mica (ilita). Foi observada, ainda, a participação do mineral quartzo ( $\mathrm{d} 001=3,35 \AA$ ) no conjunto dos minerais presentes na argila. Com o auxílio do planejamento fatorial para os dois corantes, verificou-se a influência significativa no processo da variável massa, velocidade de agitação e temperatura. Obtiveram-se resultados satisfatórios na redução da concentração por adsorção, mostrando-se que a amostra em estudo é eficaz para a remoção dos corantes ácido Nylosan Blue e reativo Azul anil Op.

Palavras-chave: adsorção, corantes, argilas.

\begin{abstract}
The textile industry process, especially in dyeing and finishing steps, requires a large volume of water. The elimination of these toxic products is currently one of the most important subjects in pollution control, which has led researchers to seek new techniques and more powerful tools to reduce or eliminate the toxicity of wastewater formed in its different processes, always taking into account efficiency, low costs and the laws and regulations aimed at environmental protection. In this study we evaluated the application of a clay waste in processes of wastewater treatment for removal of textile dyes. A study was conducted to characterize the adsorbent through the analysis of surface area and pore volume (BET), as well as the analysis of the presence of smectite group minerals (X-ray diffraction). The optimization of the adsorptive process through the technique of factorial design was used. The BET analysis showed that the heat treatment caused a reduction in the surface area of $13.3 \%$. However caused an increase of $21.16 \%$ in the pore size. The analysis of X-ray diffractograms of the samples indicated in nature, therefore, the presence of mineral groups smectite, kaolinite and mica (illite). The mineral quartz participation (d001 = 3.35 $\AA$ ) was also observed in all the minerals found in clay. With the help of factorial design for the two dyes, there was a significant influence in the process of variable mass, agitation speed and temperature. We obtained satisfactory results in the
\end{abstract}


MELLO, V. F. B.; GAMA, J.; FERREIRA, J. M.; BARAUNA, O. S.; JUCÁ, J. F. T., MOTTA SOBRINHO, M. A. revista Matéria, v. 18, n. 04, pp. $1467-1482,2013$. reduction of concentration by adsorption, being effective for the removal of acid dyes and reactive Nylosan Blue Indigo Blue Op

Keywords: adsorption, dyes, clays.

\section{INTRODUÇÃO}

$\mathrm{O}$ avanço nas atividades industriais nos últimos anos tem provocado novos problemas devido à eliminação de rejeitos tóxicos, provenientes de subprodutos gerados pela indústria, e com isso a crescente preocupação em torno da contaminação de águas naturais. Dentro deste contexto, o setor têxtil apresenta um especial destaque devido à geração de grandes volumes de efluentes, os quais, quando não corretamente tratados, podem causar sérios problemas de contaminação ambiental $[\underline{1}, \underline{2}]$.

O processamento têxtil envolve três etapas de produção: formação dos fios; formação dos tecidos e acabamento. Os estágios de formação dos fios e formação do tecido participam com uma contribuição muito pequena na geração de efluentes, em oposição aos processos molhados (acabamentos), os quais são geradores da maior parcela destes efluentes.

Os efluentes gerados pelas indústrias têxteis são bastante complexos, podendo conter uma ampla variedade de corante, dispersantes, ácidos, bases, sais, detergentes, umectantes, oxidantes, etc.

Os efluentes com corantes são um dos efluentes mais difíceis de serem tratados devido a elevada concentração de matéria orgânica (expressa em termos de DBO e DQO), de sólidos suspensos e de compostos tóxicos, além da fácil identificação do descarte pela sua cor [3]].

Os corantes lançados no meio ambiente são tóxicos a vários organismos e afetam o ecossistema principalmente pelo bloqueio da luz solar que causa uma redução na produção de oxigênio pela fotossíntese das algas e plantas presentes no corpo hídrico $[\underline{4}, \underline{5}]$.

As moléculas dos corantes são constituídas por duas partes principais: o grupo cromóforo, que dá a cor ao composto, e grupos auxiliares (auxocromos), que facilitam a sua afinidade para o substrato e que são responsáveis pela fixação do corante à fibra, tecido, couro, cabelo, papel, entre outros, conferindo uma coloração resistente à luz e à lavagem []]. Podem-se classificar os corantes pelo modo de fixação à fibra como: ácidos, reativos, diretos, azóicos, dispersivos, à cuba e pré-metalizados, dos quais os únicos que não se aplicam à indústria têxtil são os pré-metalizados e os básicos [7].

$\mathrm{Na}$ literatura são encontrados diferentes métodos que são utilizados para tratar efluentes aquosos coloridos [요미]. Não existe um método geral para descoloração de efluentes aquosos da indústria têxtil. A maior parte das indústrias realiza processos de tratamentos fundamentados na operação de precipitação/coagulação, seguida de ação biológica, principalmente com lodos ativados. As técnicas de tratamento fundamentadas em processo de coagulação seguida por flotação ou sedimentação apresentam elevada eficiência na remoção de material particulado, mas a remoção de cor e de compostos orgânicos dissolvidos é deficiente [12].

Segundo ROZZI et al. [13], a adsorção é uma das técnicas que tem sido empregada com sucesso na efetiva remoção de corantes. Este processo encontra grande aplicação industrial, pois associa baixo custo e elevadas taxas de remoção. Além disso, em alguns casos, possibilita a recuperação do corante sem perda de sua identidade química, por ser um método não destrutivo.

Adsorção é um fenômeno de superfície, o qual está relacionado com a área disponível do adsorvente em relação às massas do adsorbato e do adsorvente, $\mathrm{pH}$, temperatura, força iônica e a natureza química do adsorvente e adsorbato podendo ser reversível ou irreversível. As moléculas que estão presentes em um fluido, líquido ou gasoso, concentram-se espontaneamente sobre uma superfície sólida. Geralmente, a adsorção parece ocorrer como um resultado de forças não balanceadas na superfície do sólido e que atraem as moléculas de um fluido em contato por um tempo finito [14].

AL-QODAH [15] e TAN et al [16] investigaram a remoção do corante reativo Azul Drim KBL em xisto retortado e observaram que o aumento da concentração do corante fez com que a quantidade dele retida no adsorvente tendesse a um valor máximo.

OLIVEIRA [17] estudou a remoção do corante Remazol Black B por adsorção utilizando como adsorventes o bagaço de cana-de-açúcar e o carvão ativado em reator de batelada. Os dados de equilíbrio foram ajustados ao modelo de Langmuir e indicaram uma adsorção irreversível do corante. Foi constatado que o carvão ativado apresentou uma maior capacidade de adsorção que o bagaço de cana-de-açúcar.

A quantidade máxima de corante removida pode variar drasticamente e irá depender das características químicas e físicas dos adsorventes, pois tais propriedades estão diretamente relacionadas com os processos de quimissorção e fisissorção do adsorvato.

As características de cada corante também não podem ser desprezadas no processo de adsorção. O tamanho 
MELLO, V. F. B.; GAMA, J.; FERREIRA, J. M.; BARAUNA, O. S.; JUCÁ, J. F. T., MOTTA SOBRINHO, M. A. revista Matéria, v. 18, n. 04, pp. 1467-1482, 2013. destas moléculas possibilita uma difusão apenas parcial, principalmente em adsorventes com elevada microporosidade [18]. A Tabela 1 apresenta um resumo de aplicações de argilas na remoção de corantes.

Tabela 1: Adsorção de diversos corantes em vários adsorventes

\begin{tabular}{|c|c|c|c|}
\hline ADSORVENTE & ADSORBATO & $\begin{array}{l}\text { Q MAX } \\
(M G / G)\end{array}$ & REFERÊNCIA \\
\hline Terra de branqueamento virgem & Asucryl red GRL $200 \%$ & 84,03 & [19] \\
\hline Terra de branqueamento usada & Asucryl red GRL $200 \%$ & 73,00 & [19] \\
\hline Argila esmectita in natura & $\begin{array}{l}\text { Indanthrene Blue RS } \\
\text { (CI Vat Blue) }\end{array}$ & 13,92 & {$[20]$} \\
\hline Argila esmectita ácido ativada & $\begin{array}{l}\text { Indanthrene Blue RS } \\
\text { (CI Vat Blue) }\end{array}$ & 17,85 & [20] \\
\hline Casca de nozes brasileiras & Índigo Carmin & 1,09 & {$[\underline{21}]$} \\
\hline Bentonita ácido-ativada & Nylosan Blue 294 & 119,1 & [22] \\
\hline Sepiolite & Nylosan Red 57 & 425,0 & [23] \\
\hline Terra de filtro usada (cake) & Remazol Black B & 0,980 & {$[\underline{24]}$} \\
\hline Clinoptilolita & Amido Black 10B & 0,011 & [25] \\
\hline Clinoptilolita & $\mathrm{T}$ safranina & 0,055 & {$[\underline{25}]$} \\
\hline $\begin{array}{l}\text { Hectorite modificada (cetil } \\
\text { trimetil brometo de amônio) }\end{array}$ & Vermelho congo & 182 & {$[\underline{26}]$} \\
\hline $\begin{array}{l}\text { Hectorite modificada } \\
\text { (octadecilamina) }\end{array}$ & Vermelho congo & 197 & {$[\underline{26}]$} \\
\hline
\end{tabular}

O propósito do presente trabalho foi desenvolver e caracterizar um diferente tipo de adsorvente de baixo custo a partir de um resíduo mineral (argila), assim como estudar a sua capacidade adsortiva na remoção de corantes presentes em efluentes líquidos, visando sua aplicação em processos de tratamento de efluentes de indústrias têxteis.

\section{MATERIAIS E MÉTODOS}

\subsection{Corantes}

Os corantes utilizados foram o Nylosan Azul Brilhante (Clariant) e o Azul Anil Op (Trilimp), cujas estruturas estão representadas na Figura 1. O primeiro é um corante reativo e o segundo um corante ácido.<smiles></smiles>

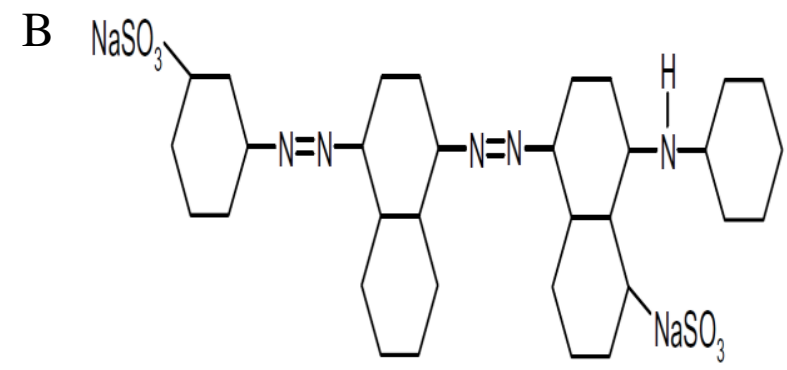

Figura 1: Estrutura do corante reativo Azul Anil fabricado (A) pela Trilimp e do Nylosan Azul (B113) (B). Fonte: PRIGIONE [27].

A concentração do corante na solução foi determinada com o auxílio da curva de calibração, obtida por meio da medição da absorbância de diferentes concentrações de soluções desse corante a um comprimento de onda máximo de $650 \mathrm{~nm}$ em um espectrofotômetro (UV-visível Thermo Genesys 10) 


\subsection{Resíduo mineral}

MELLO, V. F. B.; GAMA, J.; FERREIRA, J. M.; BARAUNA, O. S.; JUCÁ, J. F. T., MOTTA SOBRINHO, M. A. revista Matéria, v. 18, n. 04, pp. 1467 - 1482, 2013.

O material utilizado como adsorvente neste estudo foi uma amostra de argila (resíduo mineral) coletada em sua forma in natura contendo partes de todas as camadas do capeamento, que após mineração é denominado "bota-fora", na frente de lavra da Mineradora São Jorge, localizada no município de Trindade-PE, Figura 2.
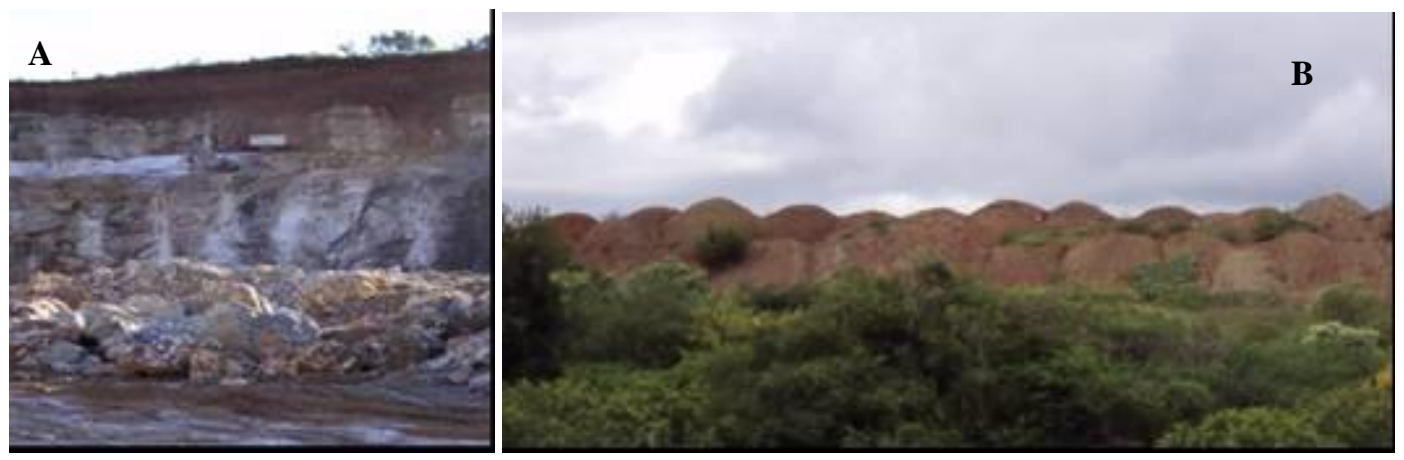

Figura 2: Vista da Frente de Lavra (A) e do resíduo da mineração (B).

A argila em sua forma in natura foi posta em bandejas de alumínio para secar em estufa de marca Fanem a $60^{\circ} \mathrm{C}$ por 8 horas. Após secagem, as argilas passaram por um Britador de mandíbulas de 1 eixo, em seguida por um moinho de rolos DECO fabricado pela DENVER a fim de reduzir sua granulometria e por fim foram amassadas com rolo de madeira (Figura 3d) para sua cominuição. Em seguida foram peneiradas em peneiras Gran Test - Bertel de aberturas 2,00, 1,19 e 0,84 mm (que correspondem a 9, 14 e 20 mesh) para obtenção das granulometrias a serem estudadas. Foram sempre tomadas as faixas passantes de cada peneira.

\subsection{Tratamento térmico do resíduo mineral}

Para cada uma das faixas granulométricas obtidas foi realizado um tratamento térmico a 200,400 e $600^{\circ} \mathrm{C}$. Para primeira temperatura, o tratamento foi realizado em estufa Fanem e para as demais em mufla Quimis Q318M21 por 6 horas. Para o tratamento térmico, os fornos e estufa foram inicialmente aquecidos até a temperatura fixada e em seguida o material foi posto para tratar. Após as 6 horas de tratamento, os equipamentos foram desligados e esperou-se três horas para retirar o material, que em seguida foi armazenado em recipientes. Em seguida foram realizados ensaios de adsorção para cada um dos corantes.

\subsection{Ensaios de adsorção}

A adsorção foi realizada a partir dos corantes ácido Nylosan Azul Brilhante e reativo Azul Anil, com uma concentração inicial conhecida. Utilizou-se em erlenmeyer de capacidade $125 \mathrm{~mL}$, o volume de $25 \mathrm{~mL}$ de uma solução de concentração $10 \mathrm{mg} / \mathrm{L}$ de corante e $0,5 \mathrm{~g}$ de argila tratada termicamente pesados em balança analítica. $\mathrm{O}$ erlenmayer contendo o adsorvente e o adsorbato foi submetido à agitação de 450 rpm durante 60 minutos em mesa agitadora Quimis Q225M.

Decorridos os 60 minutos, definidos a partir do ensaio cinético preliminar, a solução foi filtrada utilizando funil de vidro e papel de filtro quantitativo tarja azul de marca FMAIA. Foi feita medição da absorbância do filtrado no pico do comprimento de onda para calcular o percentual de remoção e concentração final do corante. As concentrações finais foram corrigidas pelo fator de correção do papel de filtro obtido por estudo prévio.

\subsection{Caracterização do resíduo mineral}

Difração de Raios X

Para a realização desta análise, a amostra de argila foi seca a $100^{\circ} \mathrm{C}$, por período de 48 horas, desagregada moída em almofariz de porcelana e peneirada em peneira ABNT no 200 (\# 0,074 mm). A amostra assim preparada foi referenciada como in natura, com o objetivo de torná-la diferenciada das amostras submetidas ao tratamento térmico a 200,400 e $600^{\circ} \mathrm{C}$.

A análise por difração de raios $\mathrm{X}$ foi realizada em um difratômetro de marca Rigaku, modelo Ultima, operando com tensão de $40 \mathrm{kV}$ e corrente de $20 \mathrm{~mA}$, utilizando radiação K-alfa do cobre. As distâncias interplanares, em todos os difratogramas, foram expressas em ângstrons $(\AA)$.

A amostra in natura preliminarmente preparada foi colocada em lâmina de vidro escavada e submetida à difração de raios $X$, percorrendo a região entre $2 \theta=2^{\circ}$ e $2 \theta=60^{\circ}$. O difratômetro de raios $X$ operou com 
MELLO, V. F. B.; GAMA, J.; FERREIRA, J. M.; BARAUNA, O. S.; JUCÁ,

J. F. T., MOTTA SOBRINHO, M. A. revista Matéria, v. 18, n. 04, pp. 1467 - 1482, 2013. tensão de $40 \mathrm{kV}$ e corrente de $20 \mathrm{~mA}$, utilizando radiação K-alfa do cobre e velocidade do goniômetro de $2^{\circ}$ por minuto.

Área Superficial Específica (Método de BET)

As superfícies específicas das argilas foram avaliadas através do método BET (Braunauer-Emmett-Teller) o qual mediu a adsorção isotérmica do $\mathrm{N}_{2}$ baseada na equação BET.

A técnica de adsorção e dessorção de gás nitrogênio $\left(\mathrm{N}_{2}\right)$ é utilizada para a determinação da área superficial específica por unidade de massa, volume de poros e tamanho médio de poros. A análise pelo método BET (Brunauer-Emmett-Teller) consiste na medida da fisissorção (adsorção física) de um gás inerte $\left(\mathrm{N}_{2}\right)$. $\mathrm{O}$ método baseia-se na determinação do volume de $\mathrm{N}_{2}$ adsorvido a diversas pressões relativas, na temperatura do nitrogênio líquido $(77 \mathrm{~K})$, a pressões relativas $(\mathrm{P} / \mathrm{Po})$. Os espectros foram obtidos em um analisador da marca Micromeritics, modelo ASAP 2010, munido de software para determinar a área superficial (SBET), porosidade (tipo de poro e distribuição do tamanho de poro) e volume total de poros (método Barret-JoynerHalenda, BJH). As análises foram realizadas no Instituto Tecnológico de Pernambuco (ITEP). A amostra foi previamente aquecida por $72 \mathrm{~h}$ a $150^{\circ} \mathrm{C}$ para remover umidade e outros materiais existentes nas áreas superficiais e dos poros.

\subsection{Otimização do processo de adsorção}

Definida a melhor argila in natura ou termicamente tratada em suas diferentes granulometrias, foi elaborado um planejamento experimental fatorial completo $2^{3} \mathrm{com}$ auxílio do software Statistica versão 6.0. Para tanto foram definidas como variáveis de entrada a temperatura durante a adsorção, a massa da argila, a agitação e como variável de resposta a capacidade de adsorção da argila (q). Os valores máximos, mínimos e ponto central dos parâmetros experimentais estão dispostos na Tabela 2.

Tabela 2: Níveis dos parâmetros para a realização do planejamento experimental.

\begin{tabular}{|c|c|c|c|}
\hline náveis & $\mathbf{( - 1 )}$ & $\mathbf{0}$ & $\mathbf{( + 1 )}$ \\
\hline Mariáveis & 0,5 & 1,5 & 2,5 \\
\hline Agitação $(\mathbf{r p m})$ & 50 & 150 & 250 \\
\hline Temperatura $\left({ }^{\mathbf{0}} \mathbf{C}\right)$ & 30 & 50 & 70 \\
\hline
\end{tabular}

O valor da quantidade adsorvida (q) foi obtido a partir da Equação 1.

$$
q=\frac{\left(C_{i}-C_{f}\right) \cdot v}{m}
$$

Onde q: quantidade adsorvida (mg do adsorbato/g de adsorvente); Ci: Concentração inicial da solução (mg/L); Cf: Concentração final da solução (mg/L); v : Volume da solução (L) e m: Massa do adsorvente (g).

Os ensaios de adsorção nesta etapa foram realizados nas condições estabelecidas pelo planejamento experimental em incubadora shaker de marca Marconi e modelo MA420, com volumes de $50 \mathrm{~mL}$ em erlenmayers de $250 \mathrm{~mL}$ com a concentração do corante de $10 \mathrm{mg} / \mathrm{L}$. Após a realização dos ensaios de adsorção as amostras foram centrifugadas em centrífuga Quimis, modelo R222T204, numa rotação de 5000 rpm durante 15 minutos para que fosse separado o material argiloso e o sobrenadante, o qual foi filtrado em papel de filtro faixa azul. A concentração final do filtrado foi determinada pelo espectrofotômetro UV-Vis. Em estudo prévio foi quantificada a adsorção do corante pelo papel do filtro em diversas concentrações, permitindo remover este efeito no cálculo da adsorção.

\section{RESULTADOS E DISCUSSÃO}

\subsection{Tratamento da argila}

Esta etapa teve por objetivo maximizar as propriedades de adsorção do material em relação a cada corante. A interação entre o adsorvente e os adsorvatos (corantes) será função das suas propriedades físico-químicas, como o tamanho da molécula do corante, área superficial, volume e tamanho dos poros do adsorvente. $\mathrm{O}$ tratamento térmico pode alterar a distribuição do tamanho dos poros e da área superficial. Todavia, este tratamento tem um custo considerável e só deverá ser realizado caso realmente haja um incremento significativo no processo adsortivo. Como os corantes apresentam características distintas, os resultados para cada corante serão apresentados separadamente. 
Corante Ácido Nylosan Azul Brilhante

Foi então preparada uma solução aquosa do corante Nylosan Azul Brilhante, cuja concentração inicial foi de $9,98 \mathrm{mg} / \mathrm{L}$, conforme Tabela 3.

Conforme pode ser verificado, pela Tabela 3, obteve-se concentrações finais variando entre 3,54 e 7,23 mg/L. A remoção máxima foi de $64,5 \%$, o que corresponde à uma capacidade de adsorção de $0,32 \mathrm{mg} / \mathrm{g}$. Sendo assim, para este corante, o mais indicado é utilizar a argila termicamente tratada a $600^{\circ} \mathrm{C}$ e granulometria de 14 mesh/Tyler. Todos os valores finais de concentração foram corrigidos pelo fator de correção do papel de filtro, obtido através da avaliação da adsorção em diferentes concentrações (curva de calibração).

Tabela 3: Resultados das concentrações finais, em mg/L, para cada temperatura e granulometria da argila para o Nylosan Azul Brilhante.

\begin{tabular}{|l|c|c|c|c|}
\hline Peneiras Temperaturas & In natura & $\mathbf{2 0 0}^{\circ} \mathrm{C}$ & $\mathbf{4 0 0}^{\circ} \mathrm{C}$ & $\mathbf{6 0 0}^{\circ} \mathbf{C}$ \\
\hline $\mathbf{9}$ mesh/Tyler & 6,47 & 7,23 & 6,03 & $\mathbf{4 , 7 4}$ \\
\hline $\mathbf{1 4}$ mesh/Tyler & 6,02 & 5,01 & 6,48 & $\mathbf{3 , 5 4}$ \\
\hline $\mathbf{2 0}$ mesh/Tyler & $\mathbf{6 , 1 6}$ & $\mathbf{5 , 6 6}$ & $\mathbf{4 , 2 8}$ & $\mathbf{4 , 6 0}$ \\
\hline
\end{tabular}

Corante Reativo Azul Anil Op

Utilizando-se $25 \mathrm{ml}$ de uma solução aquosa de 11,26 mg/L do corante Azul Anil op, com 0,5 de argila, o experimento apresentou soluções com concentrações finais (Tabela 4) variando entre 0,020 e 0,240 mg/L. Desta forma, pode-se definir a utilização da argila in natura com granulometria $14 \mathrm{mesh} /$ Tyler como adsorvente para este trabalho. A remoção foi de até 97,87\%, com capacidade de adsorção de 0,56 mg/g.

Tabela 4: Resultados finais de concentrações, em mg/L, para cada temperatura e granulometria da argila para o Reativo Azul Anil Op.

\begin{tabular}{|c|c|c|c|c|}
\hline & In natura & $\mathbf{2 0 0}^{\circ} \mathrm{C}$ & $\mathbf{4 0 0}^{\circ} \mathrm{C}$ & $\mathbf{6 0 0}^{\circ} \mathrm{C}$ \\
\hline $\mathbf{9}$ mesh/Tyler & 0,0829 & 0,2398 & 0,1092 & $\mathbf{0 , 0 9 1 7}$ \\
\hline $\mathbf{1 4}$ mesh/Tyler & 0,0201 & 0,1180 & 0,0779 & $\mathbf{0 , 2 0 9 7}$ \\
\hline $\mathbf{2 0}$ mesh/Tyler & $\mathbf{0 , 0 3 8 9}$ & $\mathbf{0 , 1 6 0 7}$ & $\mathbf{0 , 0 7 0 3}$ & $\mathbf{0 , 1 7 8 3}$ \\
\hline
\end{tabular}

\subsection{Caracterização do resíduo mineral}

Difração de raios $\mathrm{X}$

A amostra in natura revelou a presença de minerais do grupo da esmectita, e a possibilidade de ocorrência de minerais dos grupos da vermiculita e/ou clorita, sugerida pelo fato da reflexão interplanar basal em torno de $15 \AA$ Á (d001) da esmectita poder estar se superpondo a pico pouco intenso em torno de $14 \AA$ (d001), representativo dos outros mencionados minerais. Para tanto, o argilomineral foi tratado com etilenoglicol, para elucidar quais minerais estão presente, de acordo com o procedimento sugerido por Souza Santos [28]. A amostra in natura apresentou, quando glicolada, mudança do pico de $15 \AA$ (d001) para $18 \AA$ (d001). Esse comportamento é representativo dos minerais do grupo da esmectita. O referido deslocamento não revelou o surgimento de pico em torno de $14 \AA$ atribuível à vermiculita ou clorita. A permanência do pico de $10 \AA$ (d001) confirma a existência de mica ilita trioctaédrica, pela não destruição da estrutura mineral à temperatura de $600^{\circ} \mathrm{C}$. A essa mesma temperatura, o desaparecimento do pico de $7 \AA$ indica que ele é representativo da caulinita (d001), que, pelo aquecimento, transforma-se em metacaulinita por desidroxilação e perda da estrutura por distorções dos íons-alumínio na camada octaédrica, segundo Souza Santos [28]. Os difratogramas da análise de raios $\mathrm{X}$ da amostra glicolada e aquecida a $600^{\circ} \mathrm{C}$ encontram-se representados, respectivamente, nas Figuras 4 e 5. Para efeito comparativo, a Figura 6 mostra os difratogramas das análises da amostra in natura e nas diferentes condições de tratamento.

Desta forma, pôde-se concluir que a partir da análise dos difratogramas de raios $\mathrm{X}$ das amostras in natura (Figura 7), apoiada na interpretação dos difratogramas das análises das amostras submetidas a tratamentos químicos e térmicos, indicou, portanto, a presença dos grupos minerais esmectita, caulinita e mica (ilita). Foi 
MELLO, V. F. B.; GAMA, J.; FERREIRA, J. M.; BARAUNA, O. S.; JUCÁ, J. F. T., MOTTA SOBRINHO, M. A. revista Matéria, v. 18, n. 04, pp. 1467 - 1482, 2013. observada, ainda, a participação do mineral quartzo ( $\mathrm{d} 001=3,35 \AA$ ) no conjunto dos minerais presentes na argila.

Análise da área superficial e do volume de poros

A análise de BET demonstrou (Tabela 5) que o tratamento térmico provocou uma redução na área superficial de 13,3\%. Todavia provocou um aumento no tamanho dos poros de 21,16\%. Como alguns corantes apresentam a estrutura com dimensões elevadas, o aumento da porosidade pode ter sido um dos fatores que contribuíram para a melhoria da adsorção do corante Nylosan azul brilhante.

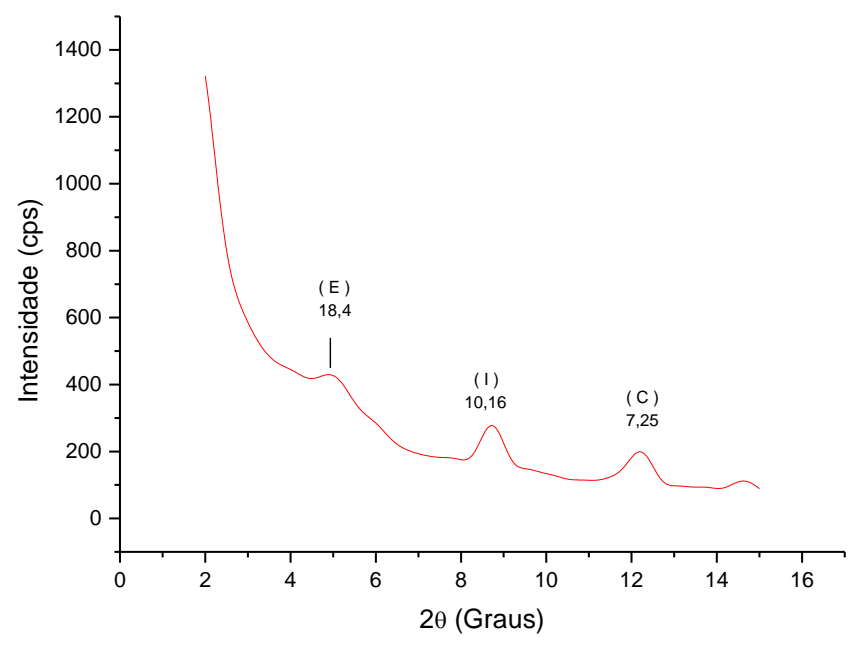

Figura 4: Difratograma da amostra da argila glicolada mostrando picos representativos das reflexões basais (d001) da esmectita (E), Ilita (I) e caulinita (C).

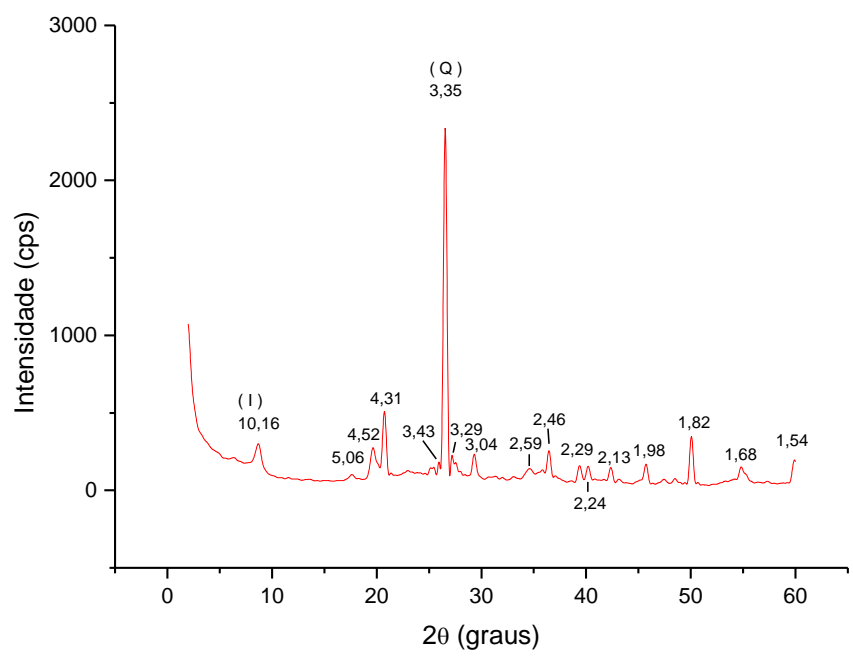

Figura 5: Difratograma da amostra da argila aquecida a $600^{\circ} \mathrm{C}$, mostrando a ausência dos picos representativos das relfexões basais $\left(\mathrm{d}_{001}\right)$ da esmectita $(\mathrm{E})$ e caulinita $(\mathrm{C})$. 
MELLO, V. F. B.; GAMA, J.; FERREIRA, J. M.; BARAUNA, O. S.; JUCÁ, J. F. T., MOTTA SOBRINHO, M. A. revista Matéria, v. 18, n. 04, pp. 1467 - 1482, 2013.

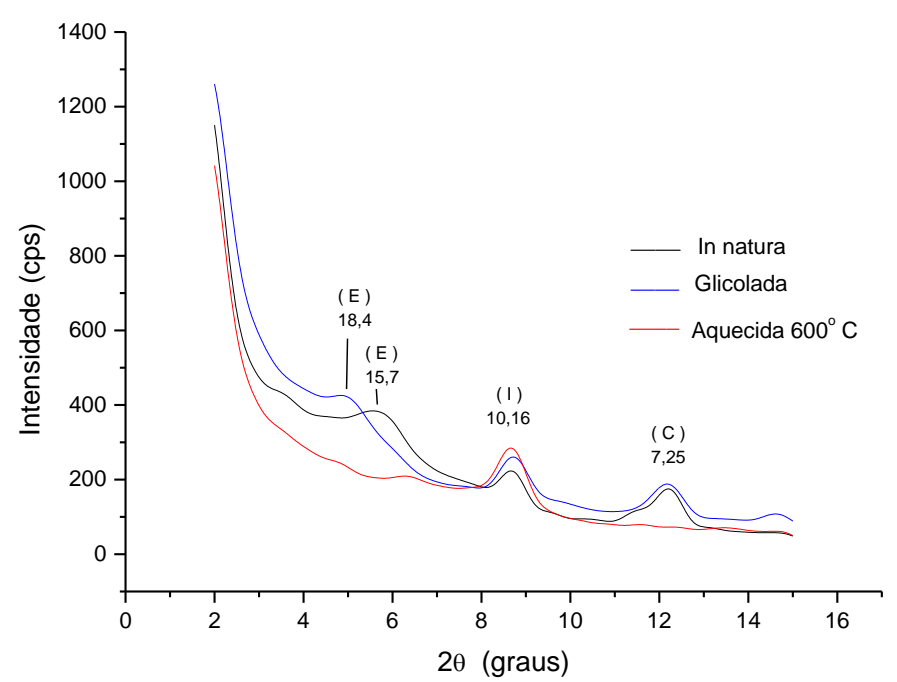

Figura 6: Difratogramas da argila revelando o deslocamento do pico representativo das reflexões basais $\left(\mathrm{d}_{001}\right)$ da esmectita in natura, de $15 \AA$, para 18 Å, após glicolagem e o desaparecimento dos picos da esmectita e da caulinita, após aquecimento.

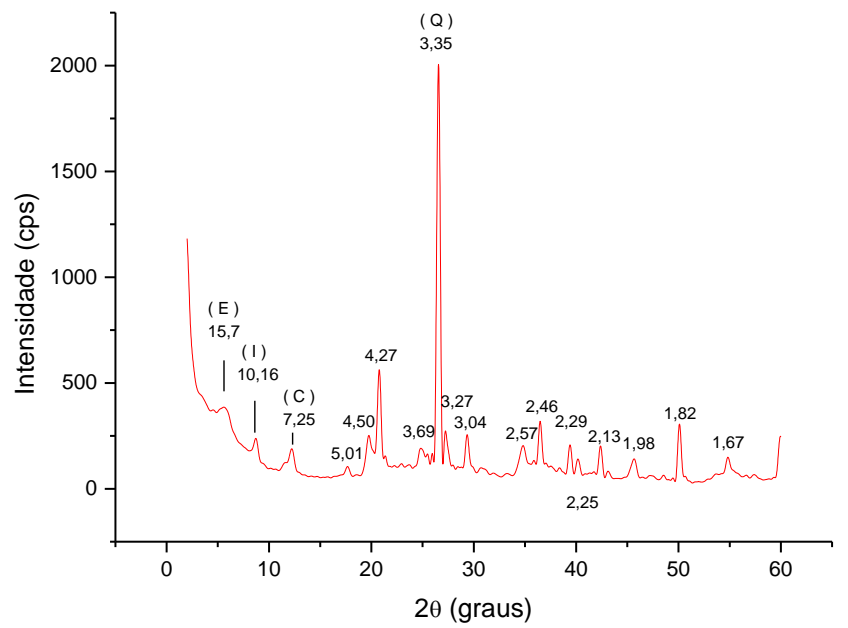

Figura 7: Difratograma da amostra da argila in natura evidenciando reflexões basais (d001) da esmectita (E), ilita (I), caulinita (C) e quartzo (Q).

Tabela 5: Resultados da análise de área superficial e do diâmetro de poro para as argilas estudadas

\begin{tabular}{|l|c|c|}
\hline & Área Superficial $\left(\mathrm{m}^{2} / \mathrm{g}\right)$ & $\begin{array}{c}\text { Diâmetro médio do } \\
\text { poro }(\mathrm{nm})\end{array}$ \\
\hline Argila "in natura" & \multicolumn{1}{|c|}{46,68} & 2,728 \\
\hline Argila Tratada a $600^{\circ} \mathrm{C}$ & 40,48 & 3,300 \\
\hline
\end{tabular}

Ao se comparar as isotermas de SING et al.[29], com as das argilas, tanto a bruta como a tratada termicamente (Figuras 8a e 8b), verifica-se que ambas são do tipo IV. A histerese entre a adsorção e a dessorção é provocada por condensação capilar que ocorre nos mesoporos. A parte incial desta isoterma é atribuída à adsorção mono-multicamada, na parte não porosa ou mesoporosa do adsorvente. Ainda segundo este autor, as isotermas do tipo IV são características de adsorventes mesoporosos industriais.

SING et al. [20] classificam os tamanhos de poros dos adsorventes como: macroporos, os que possuem diâmetros maiores que $50 \mathrm{~nm}(0,05 \mu \mathrm{m})$; os mesoporos entre 2 e $50 \mathrm{~nm}$; e os microporos com diâmetros menores que $2 \mathrm{~nm}$. Desta forma, pode-se verificar através da Figura 9, que o tratamento térmico provocou um aumento mais substancial para os mesoporos (área pontilhada). 
MELLO, V. F. B.; GAMA, J.; FERREIRA, J. M.; BARAUNA, O. S.; JUCÁ, J. F. T., MOTTA SOBRINHO, M. A. revista Matéria, v. 18, n. 04, pp. 1467 - 1482, 2013.

Através da Figura 10, verifica-se que este ganho de volume de poros, refletido na área superficial, foi principalmente para as faixas entre 10,4 e 5,9 $\mathrm{nm}$ (área pontilhada).

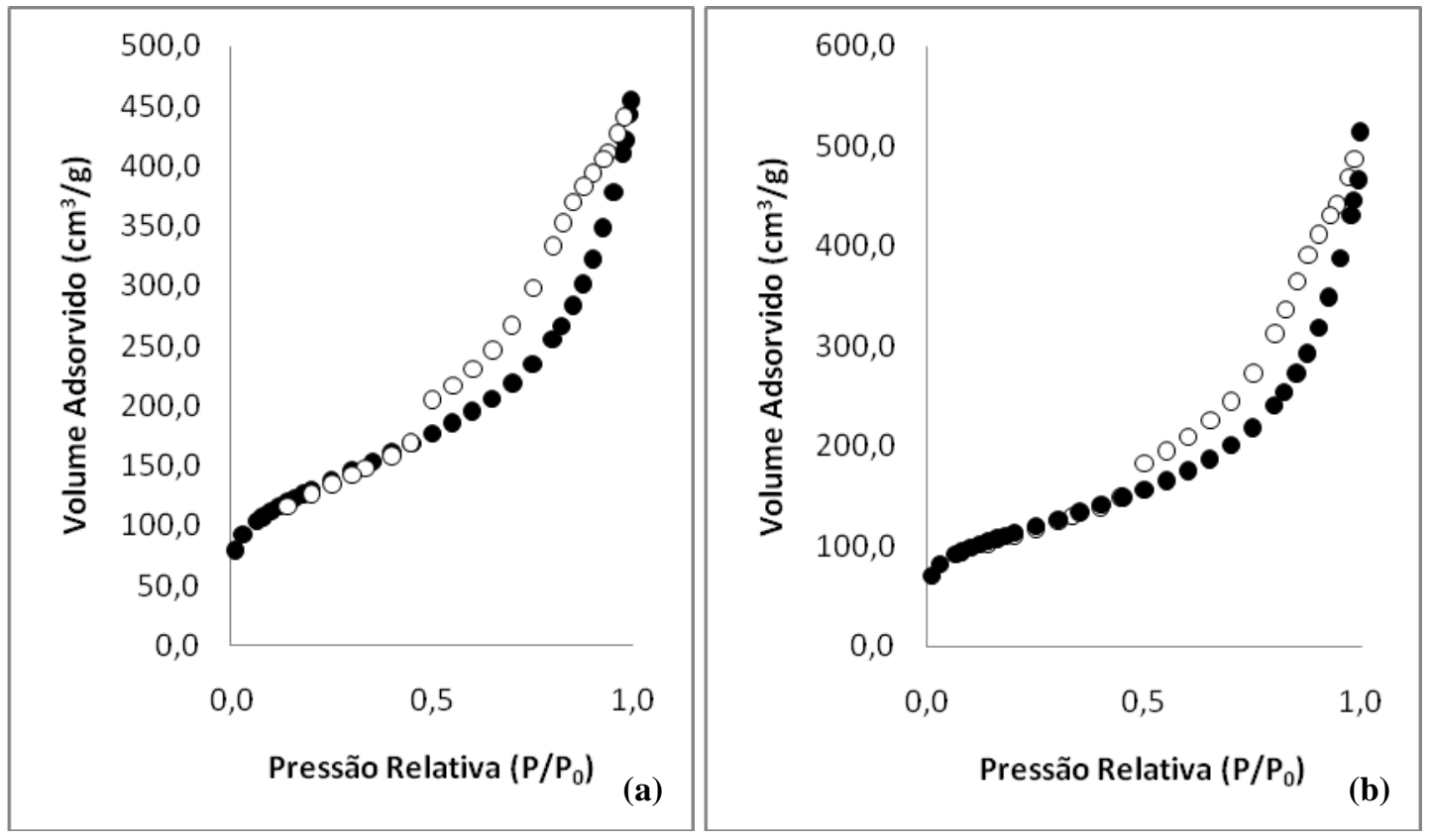

Figura 8: Isotermas de adsorção de Nitrogênio (análise BET) para a argila in natura (a) e a argila calcinada a $600^{\circ} \mathrm{C}$ (b).

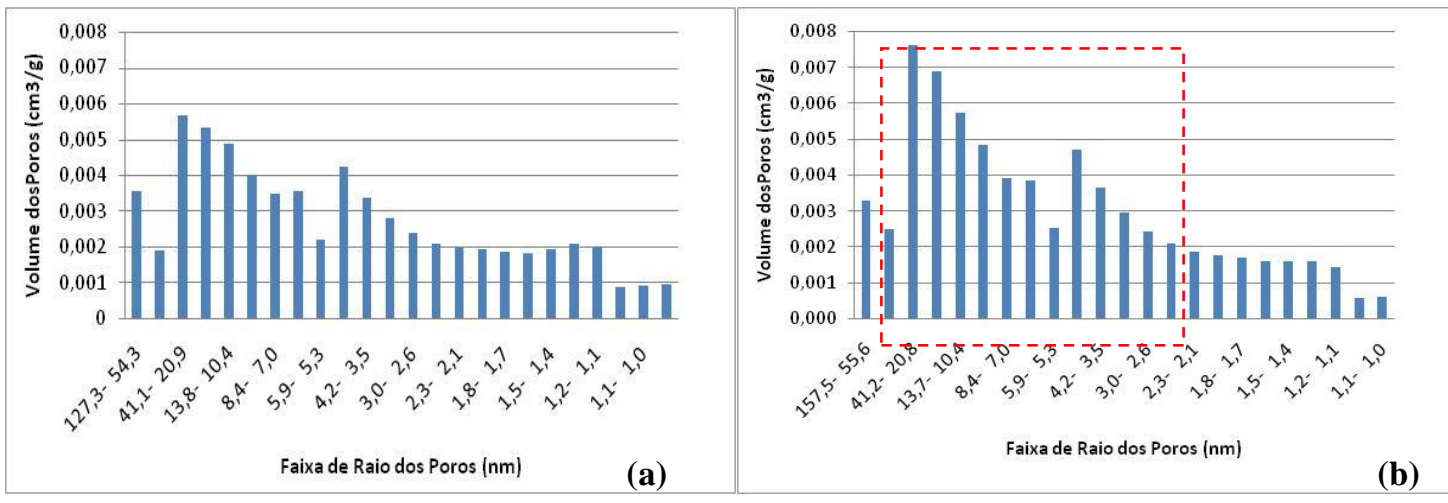

Figura 9: Distribuição de volume de poros para as diferentes faixas de tamanho de poro para a argila in natura (a) e a argila calcinada a $600^{\circ} \mathrm{C}(\mathrm{b})$.

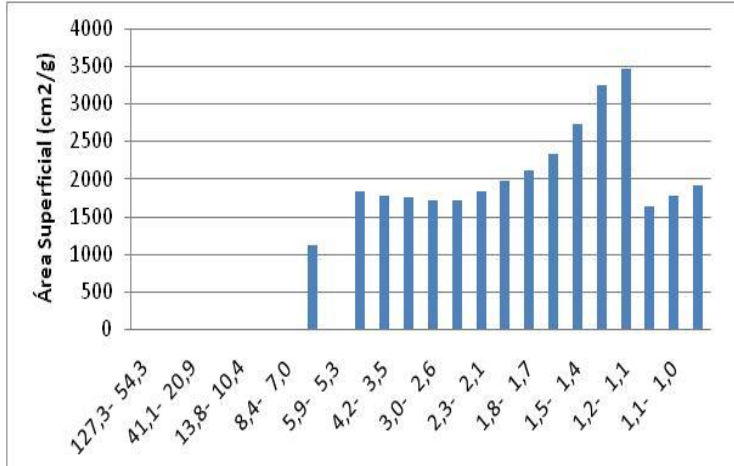

Faixa de Raio dos Poros (nm)

(a)

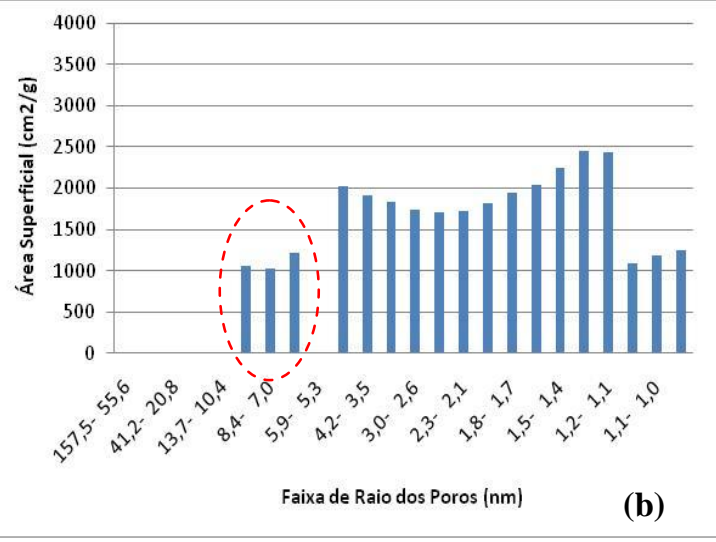

Figura 10: Distribuição da área superficial para as diferentes faixas de tamanho de poro para a argila in natura (a) e a argila calcinada a $600{ }^{\circ} \mathrm{C}(\mathrm{b})$. 
MELLO, V. F. B.; GAMA, J.; FERREIRA, J. M.; BARAUNA, O. S.; JUCÁ, J. F. T., MOTTA SOBRINHO, M. A. revista Matéria, v. 18, n. 04, pp. 1467 - 1482, 2013.

\subsection{Otimização do processo de adsorção}

Uma vez definido o adsorvente, partiu-se para a otimização do processo adsortivo, analisando a influência dos parâmetros massa, agitação e temperatura na capacidade de adsorção (q) da argila. Os resultados serão apresentados inicialmente para o corante Nylosan e em seguida para o Azul anil.

Foi realizada para cada caso uma avaliação estatística, baseada nos Gráficos de Pareto e Superfície de resposta complementada pela tabela de Análise de Variância (ANOVA). A tabela da ANOVA mostra através da analise de variância, se o modelo é estatisticamente significativo e preditivo. Todos os ensaios experimentais desta etapa foram realizados em duplicata.

Otimização para o corante ácido nylosan azul brilhante

A matriz do planejamento com as combinações dos níveis das variáveis de entrada assim como os resultados experimentais obtidos estão apresentados na Tabela 6 . A concentração inicial do corante foi de 10,461 mg/L e a massa, agitação e temperatura seguiram os valores estipulados no planejamento.

Através da Tabela 6 verifica-se que a condição ótima de agitação, massa e temperatura utilizadas nos ensaios de adsorção, a fim de se obter a maior concentração final de corante por $\mathrm{g}$ de adsorvente, ocorreu no experimento 4. Neste experimento as condições experimentais foram ajustadas para uma temperatura de $30^{\circ} \mathrm{C}$, agitação de $250 \mathrm{rpm}$, utilizando $0,5 \mathrm{~g}$ da argila tratada a $600{ }^{\circ} \mathrm{C}$ com granulometria $14 \mathrm{mesh} / \mathrm{Tyler}$.

Tabela 6: Resultado do planejamento experimental para o corante Nylosan Azul Brilhante

\begin{tabular}{|c|c|c|c|c|}
\hline Variáveis & $\begin{array}{c}\text { Massa } \\
\text { experimentos }\end{array}$ & $\begin{array}{c}\text { Agitação } \\
(\mathbf{r p m})\end{array}$ & $\begin{array}{c}\text { Temp. } \\
\left({ }^{\mathbf{}} \mathbf{C}\right)\end{array}$ & $\begin{array}{c}\mathbf{q} \text { médio } \\
(\mathbf{m g} / \mathbf{g})\end{array}$ \\
\hline 1 & 1 & 1 & 1 & 0,0800 \\
\hline 2 & -1 & 1 & -1 & 0,0927 \\
\hline 3 & -1 & 1 & 1 & 0,1990 \\
\hline 4 & 1 & -1 & 1 & 0,2378 \\
\hline 5 & 1 & -1 & -1 & 0,0730 \\
\hline 6 & -1 & -1 & 1 & 0,1635 \\
\hline 7 & -1 & -1 & -1 & 0,2051 \\
\hline 8 & 0 & 0 & 0 & 0,1149 \\
\hline 9 & 0 & 0 & 0 & 0,1207 \\
\hline 10 & 0 & 0 & 0 & 0,1175 \\
\hline 11 & & & & \\
\hline
\end{tabular}

Através do gráfico de Pareto (Figura 11) é possível verificar graficamente a influência de cada variável e a interação entre cada uma delas no processo em estudo. Neste gráfico (Figura 11), as barras (fatores) que graficamente ultrapassam a linha de significância $(\mathrm{p}=0,05)$ exercem uma influência estatisticamente significativa sobre o resultado.

Analisando a Figura 11 pode-se inferir que a variável de maior significância para este processo adsortivo, foi a quantidade de adsorvente representado pela massa, seguida da agitação e depois pela temperatura. Observase assim o efeito predominante das variáveis de forma independente. Ainda foram verificados efeitos significativos, menos predominantes, no processo pela interação das variáveis massa e agitação de massa e temperatura.

A Figura 12 (A) representa a superfície de resposta para o corante Nylosan, através da qual se observa que, quanto menor a massa e quanto maior a agitação, maior será a quantidade de corante adsorvida (q). Na Figura 12 (B), observa-se uma discreta influência da temperatura para um aumento da capacidade adsortiva do adsorvente com o decréscimo da quantidade de massa. 
MELLO, V. F. B.; GAMA, J.; FERREIRA, J. M.; BARAUNA, O. S.; JUCÁ, J. F. T., MOTTA SOBRINHO, M. A. revista Matéria, v. 18, n. 04, pp. 1467 - 1482, 2013. $\mathrm{p}=, 05$

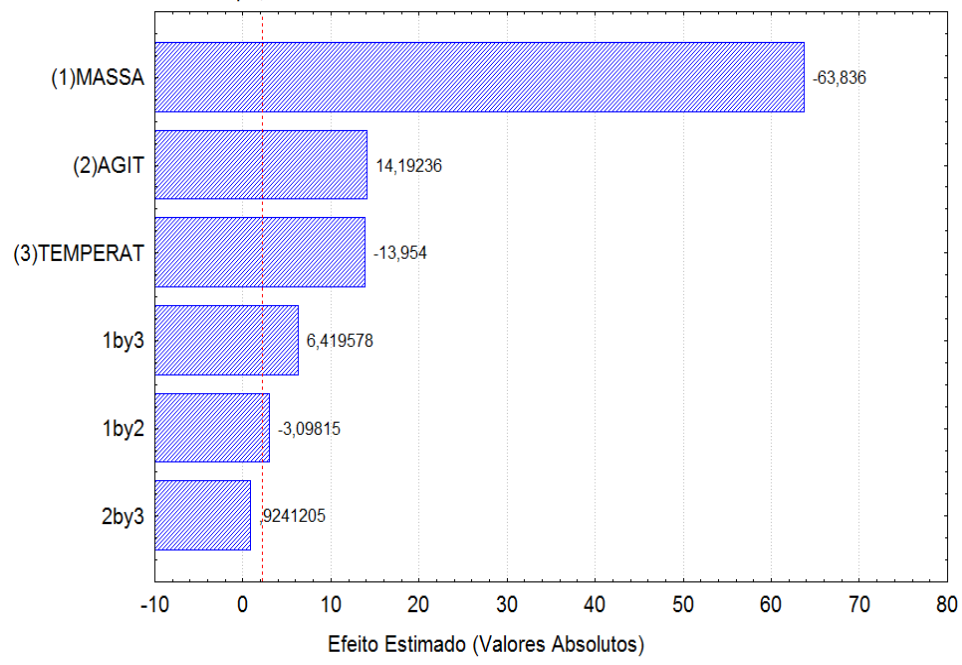

Figura 11: Gráfico de Pareto do sistema corante nylosan/argila tratada
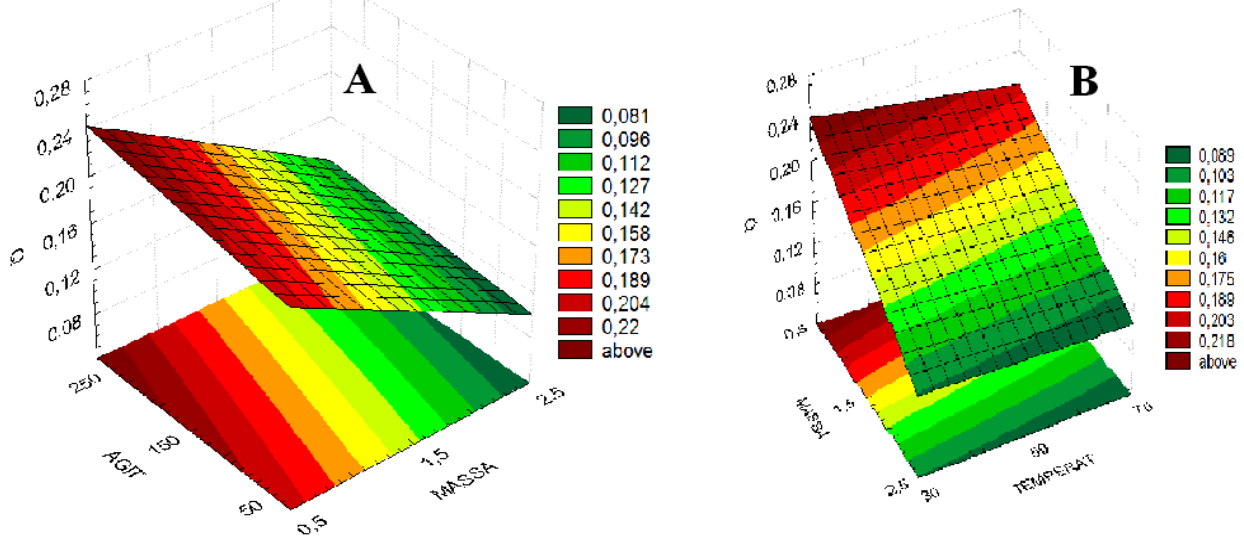

Figura 12: Superfície de resposta para (A) massa e agitação e (B) temperatura e massa na adsorção do corante Nylosan pela argila tratada.

O modelo empírico com os parâmetros estatisticamente significativos foi obtido por regressão linear dos dados experimentais, e está representado na Equação 2:

$$
q=0,13-0,063 \mathrm{M}+0,014 \mathrm{~A}-0,014 \mathrm{~T}-0,003 \mathrm{M} \mathrm{A}+0,0063 \mathrm{M} T
$$

Na qual q é a quantidade adsorvida; M a Massa; A é a Agitação; T representa a Temperatura e M.A. e M.T. as interações massa e agitação e massa e temperatura respectivamente.

Observando-se a equação, verifica-se que o segundo termo (a massa) representou uma influência negativa sob a quantidade adsorvida. Este fato era esperado, uma vez que não houve saturação do adsorvente e uma maior massa de argila irá reduzir a razão massa adsorbato / massa de adsorvente. Esta mesma equação mostra também uma influência positiva da agitação, fato este associado à redução da resistência à transferência de massa. O sinal negativo para a temperatura pode indicar uma adsorção física. $\mathrm{O}$ efeito negativo da temperatura e dos fatores combinados (massa/agitação) indicam um decréscimo do valor da capacidade de adsorção.

Na Tabela 7, encontra-se a Tabela ANOVA. Ao comparar os valores de F calculado e F tabelado, obtém-se a razão 25,31 para regressão. De acordo com BARROS NETO [30], se o valor para regressão for maior que 1 e 5 , o modelo é significativo e preditivo respectivamente. A mesma tabela apresenta também o coeficiente de correlação $\mathrm{R}^{2}$, que quanto mais próximo de 1 , os dados experimentais são mais ajustados ao modelo, neste caso obteve-se o valor de 0,97 para este coeficiente. 
MELLO, V. F. B.; GAMA, J.; FERREIRA, J. M.; BARAUNA, O. S.; JUCÁ, J. F. T., MOTTA SOBRINHO, M. A. revista Matéria, v. 18, n. 04, pp. 1467 - 1482, 2013.

Tabela 7: Resultado da ANOVA para avaliação dos ajustes dos dados e significância estatística do modelo para o corante Nylosan Azul Brilhante.

\begin{tabular}{|l|c|c|c|}
\hline & $\begin{array}{c}\text { Soma } \\
\text { Quadrática }\end{array}$ & $\begin{array}{c}\text { Números de Grau } \\
\text { de Liberdade }\end{array}$ & $\begin{array}{c}\text { Média } \\
\text { Quadrática }\end{array}$ \\
\hline Regressão & 0,070481 & 6 & 0,0117 \\
\hline Resíduos & 0,002073 & 13 & 0,0002 \\
\hline Falta de Ajuste & 0,001870 & 2 & 0,0009 \\
\hline Erro Puro & 0,000203 & 13 & 0,00002 \\
\hline Total & 0,07 & 21 & \\
\hline Ftabelado REG & $\mathbf{2 , 9 1}$ & & \\
\hline Fcalculado & $\mathbf{7 3 , 6 7}$ & & \\
\hline \multicolumn{1}{|c|}{ Fc/Ftab } & $\mathbf{2 5 , 3 1}$ & & \\
\hline $\mathrm{R}^{2}$ & $\mathbf{0 , 9 7}$ & & \\
\hline
\end{tabular}

Otimização para o corante reativo azul anil

A matriz do planejamento para o corante reativo azul anil, com as combinações dos níveis das variáveis de entrada assim como os resultados experimentais obtidos estão apresentados na Tabela 8. A concentração inicial do corante foi de $10 \mathrm{mg} / \mathrm{L}$ e a massa, agitação e temperatura seguiram os valores estipulados no planejamento.

É possível verificar, através da Tabela 8, que a maior quantidade desse corante adsorvida pela argila foi de aproximadamente $0,52 \mathrm{mg} / \mathrm{g}$ e essa condição acontece quando a variável massa encontra-se no nível inferior, enquanto que a temperatura no nível superior (ensaio 3). Todavia, ao se comparar este com o ensaio 4, no qual a temperatura está em seu nível inferior, observa-se que a capacidade de adsorção é a mesma. Logo se pode concluir que a temperatura, dentro da faixa estudada, não exerceu influência no processo adsortivo. Este mesmo resultado será confirmado no diagrama de Pareto, a ser apresentado mais adiante.

Tabela 8: Resultado do planejamento experimental para o corante Azul anil

\begin{tabular}{|c|c|c|c|c|}
\hline Experimentos & $\begin{array}{c}\text { Massa } \\
(\mathbf{g})\end{array}$ & $\begin{array}{c}\text { Agitação } \\
(\mathbf{r p m})\end{array}$ & $\begin{array}{c}\text { Temperatura } \\
\left({ }^{\mathbf{}} \mathbf{C}\right)\end{array}$ & $\begin{array}{c}\mathbf{q} \text { médio } \\
(\mathbf{m g} / \mathbf{g})\end{array}$ \\
\hline 1 & 1 & 1 & 1 & 0,10381 \\
\hline 2 & 1 & 1 & -1 & 0,10433 \\
\hline 3 & -1 & 1 & 1 & $\mathbf{0 , 5 1 6 3 9}$ \\
\hline 4 & -1 & 1 & -1 & $\mathbf{0 , 5 1 6 5 2}$ \\
\hline 5 & 1 & -1 & 1 & 0,10208 \\
\hline 6 & 1 & -1 & -1 & 0,10073 \\
\hline 7 & -1 & -1 & 1 & 0,47097 \\
\hline 8 & -1 & -1 & -1 & 0,46767 \\
\hline 9 & 0 & 0 & 0 & 0,17194 \\
\hline 10 & 0 & 0 & 0 & 0,17203 \\
\hline 11 & 0 & 0 & 0 & 0,17129 \\
\hline
\end{tabular}

Os resultados obtidos a partir do planejamento experimental demonstraram remoção satisfatória de cor no ponto ótimo (Figura 13). 


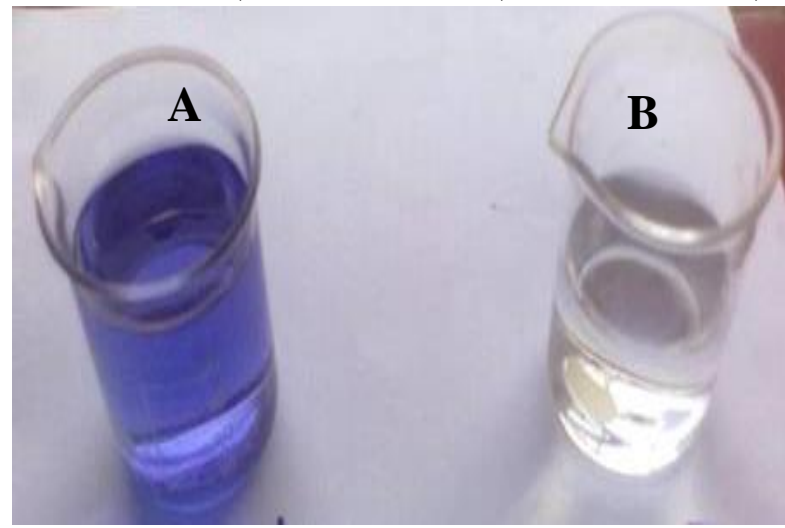

Figura 13: Foto da solução do corante reativo azul anil op na concentração de $10 \mathrm{mg} / \mathrm{L}$ antes da adsorção (A) e após (B) a adsorção nas condições do ponto ótimo.

Através do gráfico de Pareto, apresentado na Figura 14, Constatou-se que a variável de maior significância para este processo adsortivo, foi a quantidade de adsorvente, seguido da agitação. Observou-se ainda como efeito significativo, a interação das variáveis massa e agitação. Uma observação interessante é que para este sistema adsorbato/adsorvente a temperatura não apresentou influência significativa no processo.

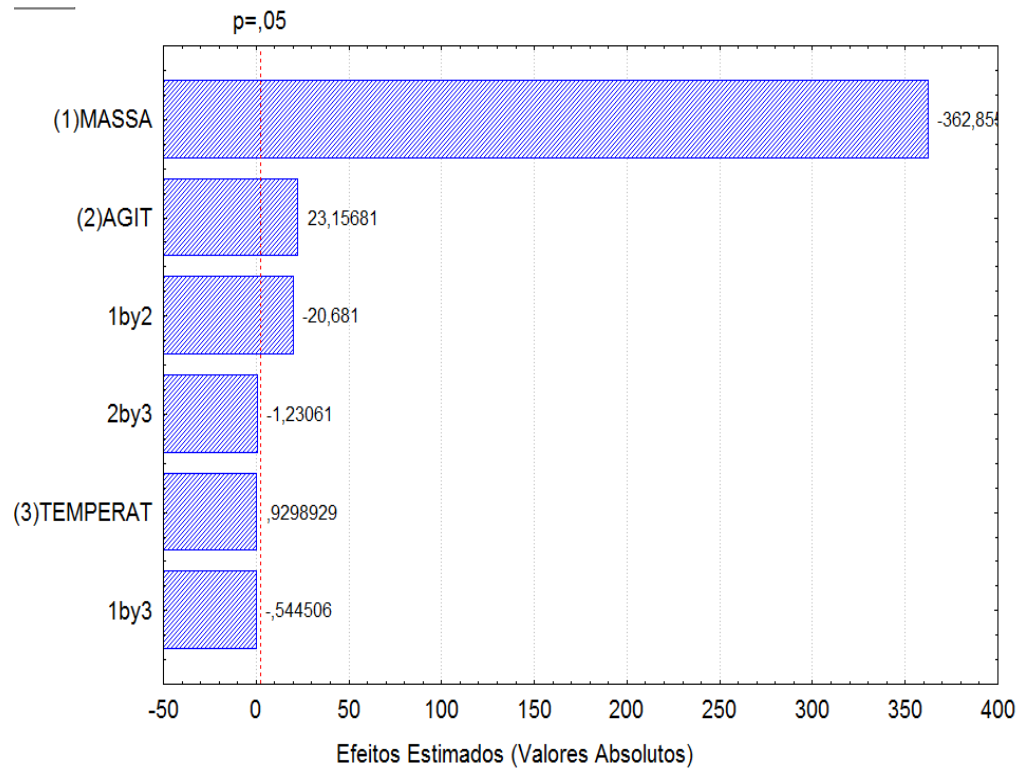

Figura 14: Gráfico de Pareto do sistema corante azul anil/argila "in natura",

A Figura 15 representa a superfície de resposta para o corante azul anil. Pode-se observar que o aumento da quantidade de corante adsorvida (q) aconteceu mediante emprego de baixas concentrações de adsorvente, independentemente da velocidade de agitação.

O modelo empírico com os parâmetros estatisticamente significativos, foram obtidos por regressão linear dos dados experimentais e está representado pela Equação 3.

$$
q=0,26-0,195 \mathrm{M}+0,012 \mathrm{~A}-0,011 \mathrm{M} . \mathrm{A}
$$

Onde $\mathrm{q}$ = quantidade adsorvida $\mathrm{M}$ = massa e M.A.= $\mathrm{a}$ interação massa e agitação.

Na Tabela 9, encontra-se o sumário da análise da variância (ANOVA), a qual indicou que o modelo é estatisticamente significativo e preditivo [20], pois a razão entre o teste $\mathrm{F}$ calculado e o tabelado foi de aproximadamente 6,62. A mesma tabela apresenta também o coeficiente de correlação $\mathrm{R}^{2}$, que quanto mais próximo de 1, os dados experimentais são mais ajustados ao modelo. Neste caso, obteve-se o valor de 0,90 para este coeficiente. 


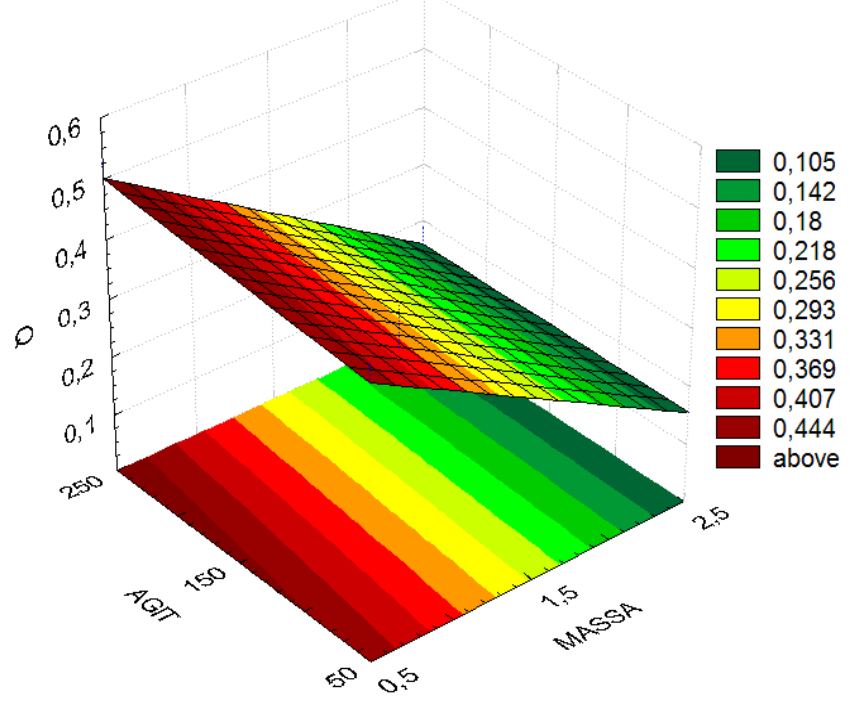

Figura 15: Superfície de resposta para o efeito da agitação e da massa na capacidade de adsorção do corante azul anil na argila "in natura".

Tabela 9: Resumo da ANOVA para avaliação dos ajustes dos dados e significância estatística do modelo para o corante azul anil.

\begin{tabular}{|l|c|c|c|}
\hline $\begin{array}{c}\text { Fonte de } \\
\text { Variação }\end{array}$ & $\begin{array}{c}\text { Soma } \\
\text { Quadrática }\end{array}$ & $\begin{array}{c}\text { Números de Grau } \\
\text { de Liberdade }\end{array}$ & $\begin{array}{c}\text { Média } \\
\text { Quadrática }\end{array}$ \\
\hline Regressão & 0,61364 & 6 & 0,1023 \\
\hline Resíduos & 0,06906 & 13 & 0,0053 \\
\hline Falta de Ajuste & 0,06900 & 2 & 0,0345 \\
\hline Erro Puro & 0,00006 & 13 & 0,00000 \\
\hline Total & 0,68 & 21 & \\
\hline Ftabelado REG & $\mathbf{2 , 9 1}$ & & \\
\hline Fcalculado & $\mathbf{1 9 , 2 5}$ & & \\
\hline Fc/Ftab & $\mathbf{6 , 6 2}$ & & \\
\hline $\mathrm{R}^{2}$ & $\mathbf{0 , 9 0}$ & & \\
\hline
\end{tabular}

Obteve-se para os dois corantes resultados satisfatórios na redução da concentração por adsorção, com remoções na faixa de 90\%. Todavia, o sistema adsortivo corante azul anil/argila "in natura" foi o que apresentou valores superiores para a capacidade de adsorção.

\section{CONCLUSÕES}

O resíduo da mineração da gipsita, mistura de argila e outros minerais, mostrou-se eficaz para a adsorção dos corantes ácido Nylosan Blue e reativo Azul anil Op. O ensaio da ativação térmica mostrou que o mesmo é necessário apenas para a adsorção do corante Nylosan, à uma temperatura de $600{ }^{\circ} \mathrm{C}$, sendo a granulometria de $14 \mathrm{Mesh} /$ Tyler a mais indicada para ambos corantes. A otimização do processo adsortivo pelo planejamento indicou que a melhor condição é para uma menor massa, maior agitação e menor temperatura, para ambos os sistemas corante/argila.

\section{AGRADECIMENTOS}

Aos Grupos de Processos e Tecnologias Ambientais (GPTA), de Resíduos Sólidos (GRS) e de Tecnologia Mineral, assim como aos Laboratórios do CETENE e de Materiais do ITEP pela estrutura cedida para a realização deste estudo. A Mineradora São Jorge pelas amostras de material argiloso cedido (resíduo da extração da Gipstita). Ao CNPq, CAPES e FACEPE pelo auxílio financeiro. 


\section{REFERÊNCIAS}

MELLO, V. F. B.; GAMA, J.; FERREIRA, J. M.; BARAUNA, O. S.; JUCÁ, J. F. T., MOTTA SOBRINHO, M. A. revista Matéria, v. 18, n. 04, pp. 1467 - 1482, 2013.

[1] KUNZ, A., ZAMORA, P. P., MORAES, S. G. M., DURAN, N., "Novas tendências no tratamento de efluentes têxteis", Química Nova, v.25, n.1, pp.78-82, 2002.

[2] ANDRADE, F., "Remoção de cor de efluentes têxteis com tratamento de lodos ativados e um polieletrólito orgânico”, Dissertação de M.Sc., UFSC, Florianópolis, SC, Brasil, 2003.

[3] WESEMBERG, D., BUCHON, F., AGATHOS, S.N., "Degradation of dye containing textile effluent by the agaric white-rot fungus Clitocybula dusenii”, Biotechnology Letters, v. 24, n.12, pp. 989-993, 2003.

[4] BANAT, I.M., NIGAM, P., SINGH, D., MARCHANT, R. "Microbial decolorization of textile-dyecontaining effluents: a review”, Bioresour. Technol, v.58, n.3, pp. 217-227, 1996.

[5] AKSU, Z. "Application of biosorption for the removal of organic pollutants: a review”, Process Biochem., v. 40, n.3-4, pp. 997-1026, 2005.

[6] GUPTA, V. K.., SUHAS., “Application of low-cost adsorbents for dye removal”, Journal of Environmental Management”, v. 90, n.8, pp. 2313-2342, 2009.

[7] GUARATINE, C.C.I., ZANONI, M,V.B., “Corantes têxteis”, Química nova, v. 23, n.1, pp .1-21, 2000.

[8] WANG, Y., LIN, S., JUANG, R., "Removal of heavy metal ions from aqueous solutions using various low-cost adsorbents", Journal of Hazardous Materials, v. 102, n. 2-3, pp. 291-302, 2003.

[9] LU, X.; YANG, B, “Treatment of Wastewater Containing Azo Dye Reactive Brilliant Red x 3b Using Sequential Ozonation and Upflow", Journal of Hazardous Materials, v. 161, n.1, pp.241-245, 2009.

[10] KHOUNI, I., MARROT, B., MOULIN, P., AMAR, R. B., "Decolourization of the Reconstituted Textile Effluent by Different Process Treatments: Enzymatic Catalysis, coagulation/Flocculation and Nanofiltration Processes", Desalination, v. 268, n.1-3, pp. 27-37. 2011.

[11] AMAR, N.B., KECHAOU, N., PALMERI, J., et al., "Comparison of tertiary treatment by nanofiltration and reverse osmosis for water reuse in denim textile industry", Journal of Hazardous Materials, v. 170, n.1, pp. 111-117, 2009.

[12] CARVAlHO, T. E. M., “Adsorção de Corantes Aniônicos de Solução Aquosa em Cinza Leve de Carvão e Zeólita de Cinza Leve de Carvão”, Dissertação de M.Sc., Instituto de Pesquisas Energéticas e Nucleares/Universidade de São Paulo, São Paulo, SP, Brasil, 2010.

[13] ROZZI, A., MALPEI, F., BONOMO, L., "Textile wastewater reuse in northern Italy". Water Science Technology, v. 39, n. 5, pp. $121-128,1999$.

[14] SCHETTINO JUNIOR, M. A., “Ativação Química do Carvão de Casca de Arroz Utilizando NaOH”, Dissertação de M.Sc., Universidade Federal do Espírito Santo, Vitória, ES, Brasil, 2004.

[15] AL-QODAH, Z., “Adsorption of dyes using shale oil ash”, Water Research, v. 34, n.17, pp. 4295 4303, 2000.

[16] TAN, I.A.W.; AHMAD, A.L.; HAMEED, B.H, “Adsorption of Basic Dye on High-Surface-Area Activated Carbon Prepared from Coconut Husk: Equilibrium, Kinetic and Thermodynamic Studies", Journal of Hazardous Materials, v. 154, n.1-3, pp. 337-346, 2008.

[17] OLIVEIRA, C. C. N., "Estudos de equilíbrio e modelagem cinética da adsorção de corante têxtil e Remazol Black B" sobre bagaço de cana-de-açúcar in natura e carvão ativado, Dissertação de M.Sc., Universidade Federal de Pernambuco, Recife, PE, Brasil, 2003.

[18] HODA, N., BAYRAM, E., AYRANCI, E., "Kinetic and equilibrium studies on the removal of acid dyes from aqueous solutions by adsorpition onto actived carbon cloth", Journal of Hazardous materials, v. 137, n.1, pp. 344-351, 2006.

[19] MEZITI,C., BOUKERROUI, A., "Removal of a Basic Textile Dye from Aqueous Solution by Adsorption on Regenerated Clay”, Procedia Engineering, v. 33 , pp. 303-312, 2012.

[20] CHAARI, I., FEKI, M., MEDHIOUBC, M., et al., “Adsorption of a textile dye "Indanthrene Blue RS (C.I. Vat Blue 4)" from aqueous solutions onto smectite-rich clayey rock". Journal of Hazardous Materials. v. 172, n. 1-2, pp. 1623-1628, 2009. 
MELLO, V. F. B.; GAMA, J.; FERREIRA, J. M.; BARAUNA, O. S.; JUCÁ, J. F. T., MOTTA SOBRINHO, M. A. revista Matéria, v. 18, n. 04, pp. 1467 - 1482, 2013.

[21] BRITO, S. M. O., ANDRADE, H, M. C., SOARES, L. F., et al., "Brazil nut shells as a new biosorbent to remove methylene blue and indigo carmine from aqueous solutions". Journal of Hazardous Materials. v. 174, n.1-3, pp. 84-92, 2010

[22] ÖZCAN, A. S., ÖZCAN, A., “Adsorption of acid dyes from aqueous solutions onto acid-activated Bentonite", Journal of Colloid and Interface Science, v. 276, n. 1, pp. 39-46, 2004.

[23] ÖZCAN, A., ÖZCAN, A. S. "Adsorption of Acid Red 57 from aqueous solutions onto surfactantmodified Sepiolite”, Journal of Hazardous Materials, v. 125, n.1-3, pp. 252-259, 2005.

[24] SILVA, T. C. “Avaliação do resíduo argiloso proveniente da indústria do alumínio como adsorvente de corantes têxteis", Dissertação de M.Sc., Universidade Federal de Pernambuco, Recife, PE, Brasil, 2008.

[25] QIU, M., QIAN, C., XU, J., et al.,"Studies on the adsorption of dyes into Clinoptilolite”, Desalination, v. 243, n.1-3, pp. 286-292, 2009.

[26] XIA, C., JING, Y., JIA, Y., et al., “Adsorption properties of congo red from aqueous solution on modified hectorite: Kinetic and thermodynamic studies", Desalination, v. 265, n. 1-3, pp. 81-87, 2011.

[27] PRIGIONE, V., VARESE, G.C., CASIERI, L., et al., "Biosorption of simulated dyed effluents by inactivated fungal biomasses", Bioresource Technology, v. 99, n.9, pp. 3559-3567, 2008.

[28] SOUZA SANTOS, P., Ciência e tecnologia de argilas, 2 ed., v.1, São Paulo, Edgard Blucher, 1992.

[29] SING, K. S. W., EVERETT D. H., HAUL, R. A. W., et al., "Reporting physisorption data for gas/solid systems with Special Reference to the Determination of Surface Area and Porosity”. Pure \& Appl. Chem., v. 57, n. 4, pp. 603-619, 1985.

[30] BARROS NETO, B., SCARMINIO, J.S., BURNS, R.R., "Planejamento e otimização de experimentos", São Paulo, Campinas editora, 2001. 